\title{
THE ORIGIN OF THE TSUNAMI EXCITED BY THE 1906 SAN FRANCISCO EARTHQUAKE
}

\section{By Kuo-Fong Ma, Kenj Satake, and Hiroo Kanamori}

Lawson et al. (1910) reported a tsunami observed at Fort Point in San Francisco Bay (Fig. 1a) during the 1906 San Francisco earthquake ( $M=8 \frac{1}{4}$ ). This observation is curious because the San Francisco earthquake is generally believed to be a strike-slip earthquake for which tsunamis are not usually expected. However, the recent Loma Prieta earthquake, which occurred on a part of the rupture zone of the San Francisco earthquake, unexpectedly had a significant component of vertical fault motion, and it suggested the possibility that the San Francisco earthquake also had some vertical fault motion. To investigate this possibility, we analyzed the tsunami observed at Fort Point. Since tsunamis are primarily caused by vertical motion of the sea floor, we can constrain the extent of vertical component of fault motion using tsunami data. We show that the tsunami was caused by a local subsidence associated with a bend of the San Andreas fault offshore from the Golden Gate; no vertical fault motion was involved during the 1906 San Francisco earthquake.

We first removed the tide from the original record. Figure $1 \mathrm{~b}$ shows the detrended record for 1 hour starting from the origin time of the earthquake. A depression of the water level of about $10 \mathrm{~cm}$ is seen about 7 to $8 \mathrm{~min}$ after the origin time. The waveform shows only downward motion. The small motion immediately after the earthquake is probably due to shaking by the earthquake (Lawson et al., 1910) and is ignored in this analysis.

We computed tsunami waveforms using a finite-difference method and the actual bathymetry of San Francisco Bay (Fig. 1c). First, to determine the source location of the tsunami, we computed an inverse travel-time diagram by placing a source at the Fort Point tide gage station and propagating tsunamis backward into San Francisco Bay. The inverse travel time isochron at $8 \mathrm{~min}$ shown in Figure 1d suggests that the source of the tsunami is probably a subsidence that occurred east of the San Andreas fault.

To determine more details of the seafloor deformation responsible for the tsunami, we divided the seafloor into 15 blocks ( 4 by $5 \mathrm{~km}^{2}$ each) as shown in Figure 1d, and we inverted the observed tsunami waveform to determine the displacement for each block. The inversion is formulated as

$$
A_{j}\left(t_{i}\right) x_{j}=b\left(t_{i}\right) \text {, }
$$

where $A_{j}\left(t_{i}\right)$ is the tsunami amplitude at time $t_{i}$ due to a unit displacement at the $j$ th block, $x_{j}$ is the displacement at the $j$ th block, and $b\left(t_{i}\right)$ is the observed tide gage record at time $t_{i}$. The displacement $x_{j}$ for each block is estimated with a linear least-squares inversion of equation (1).

Figure 1e shows the vertical displacement of seafloor determined by the inversion. The displacement is mostly subsidence. The synthetic tsunami computed for the displacement field shown in Figure 1b can explain the period and the amplitude of the observed tsunami. The subsidence averaged over the 15 blocks is about $7 \mathrm{~cm}$. 

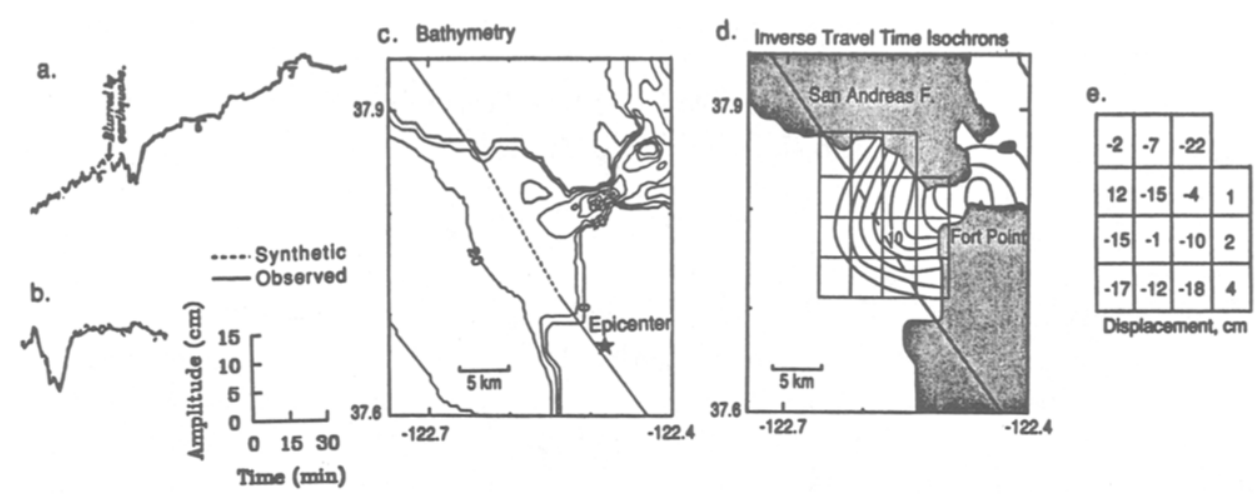

FIG. 1. (a) Tide gage record at Fort Point, San Francisco (after Lawson et al., 1910). (b) The tsunami waveform starting from the origin time of the earthquake (solid curve). The dotted curve indicates the synthetic tsunami waveform computed for the displacement field shown in (e) (c) Bathymetry near the Golden Gate. The contour lines are given at 0, 10, 20,40,60, and $80 \mathrm{~m}$. (d) Inverse tsunami travel-time isochrons from Fort Point. Contour intervals are 2 min. (e) Vertical displacements (in $\mathrm{cm}$ ) in the boxed areas shown in (d) obtained from tsunami data by inversion. The negative values indicate subsidence.

The San Andreas fault exhibits a right-stepping bend offshore from the Golden Gate as shown in Figure 1d. For this geometry, a right-lateral strike-slip fault yields a subsidence between the straight segments even if the slip is purely horizontal. Although the exact magnitude and distribution of the vertical displacement depends on the details of fault geometry, a simple numerical calculation shows that the ratio of the vertical displacement to the horizontal slip ranges from 0.01 to 0.03 for a vertical strike-slip fault extending to a depth of $12 \mathrm{~km}$. Since the horizontal slip during the 1906 San Francisco earthquake is estimated to be about $6 \mathrm{~m}$ along this segment (Lawson et al., 1910; Thatcher, 1975), a subsidence of about $10 \mathrm{~cm}$ is expected near the bend, which is consistent with that determined from the observed tsunami waveform. This agreement suggests that the cause of the tsunami is due to the local subsidence associated with the right-stepping bend of the San Andreas fault offshore from the Golden Gate, and no vertical fault motion was involved during the 1906 San Francisco earthquake.

\section{ACKNOWLEDGMENTS}

This work was partially supported by the National Science Foundation grant EAR 89-15987. Contribution No. 4963, Division of Geological and Planetary Sciences, California Institute of Technology, Pasadena, California.

\section{REFERENCES}

Lawson, A. C., G. K. Gilbert, H. F. Reid, J. C. Branner, A. O. Leuschner, G. Davidson, C. Burkhalter, and W. W. Campbell (1910). The California earthquake of April 18, 1906, Report of the state earthquake investigation commission, Carnegie Institution, 2, 369-373.

Thatcher, W. (1975). Strain accumulation and release mechanism of the 1906 San Francisco earthquake, J. Geophys. Res. 80, 4862-4872.

SEISMOLOGICAL LABORATORY

California Institute of Technology

Pasadena, California 91125

Manuscript received 2 January 1991 